\title{
Effects of diflubenzuron and mancozeb on soil microarthropods: a long-term study
}

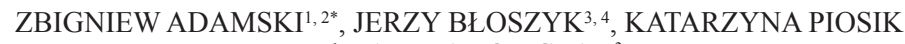 \\ and KAMILA TOMCZAK ${ }^{3}$ \\ ${ }^{1}$ Department of Animal Physiology and Developmental Biology, Adam Mickiewicz University, \\ Umultowska 89, 61-614 Poznań, Poland; e-mail: ed@amu.edu.pl \\ ${ }^{2}$ Laboratory of Electron and Confocal Microscopy, Adam Mickiewicz University, \\ Umultowska 89, 61-614 Poznań, Poland \\ ${ }^{3}$ Department of General Zoology, Adam Mickiewicz University, Umultowska 89, \\ 61-614 Poznań, Poland \\ ${ }^{4}$ Natural History Collection, Adam Mickiewicz University, Umultowska 89, 61-614 Poznań, Poland
}

(Received on 12 March 2009; Accepted on 21 July 2009)

\begin{abstract}
Soil microarthropods exposed to the pesticides mancozeb (240 $\mathrm{mg}$ per $1 \mathrm{~m}^{2}$ ) or diflubenzuron ( $7.2 \mathrm{mg}$ of diflubenzuron per $1 \mathrm{~m}^{2}$ ) were studied for 6 months after a single application. The observed taxa included Collembola, Insecta, Myriapoda, and 4 groups of mites: Actinedida (=Prostigmata), Gamasina, Uropodina, and Oribatida. Their abundance in soil was subject to seasonal fluctuations, but for a majority of taxa no significant differences were noticed between the control and exposed plots. The total number of microarthropods was insignificantly lower in exposed groups. Myriapods were the only taxon that was close to extinction after a single exposure to diflubenzuron. These data prove that soil has some buffering capacity, and this fact should always be taken into consideration when estimating the risk for the environment. However, the situation may change if the application of pesticides is repeated.
\end{abstract}

Keywords: soil microarthropods, pesticides, diflubenzuron, mancozeb, mites, insects, myriapods

\section{INTRODUCTION}

For various species, which contribute to circulation of matter, the soil is the actual habitat, where they meet their needs. Soil mesofauna is represented (among others) by mites (Acari), springtails (Collembola), and small insects (mainly larvae of Diptera and Coleoptera), which play very important roles in the process of litter decomposition and humus formation. Decline in their abundance extends this process in time. In consequence, the circulation of matter is impaired. A long-term decline in biological activity of the soil leads to a decrease in its fertility and increases the threat of soil erosion (Addison et al. 2003). Xenobiotics, e.g. pesticides, are an additional threat to soil fauna. Complex effects of pesticides on animals and plants are 
still not fully known. Pesticides are frequently sprayed above forests, mostly to kill the pests of trees. Although the majority of these xenobiotics settle down on the forest canopy, some of the sprayed chemicals reach the soil and affect the animals inhabiting it. Since pesticides are not $100 \%$ specific, they cause lethal and sublethal effects within non-target species (ADAMSKI \& ZIEMNICKI 2004, ADAMSKI et al. 2007) and their lethality may show stage-dependence (CHARMILLOT et al. 2001) and cross-resistance (REuveny \& COHEN 2004). Therefore, we decided to look more closely at the longterm toxicity of pesticides to soil fauna.

In a previous paper we reported the effect of the dithiocarbamate fungicide mancozeb on wood dust fauna (ADAMSKI et al. 2007). We showed that the majority of species reveal some susceptibility to the pesticide (i.e. show acute toxicity) in doses used in forestry. However, these laboratory experiments could not show the full complexity of the effect of mancozeb on various taxa. One must be aware of the possible effect of climate changes, uneven distribution of the toxic chemicals down the soil, etc. Moreover, the diversity of pesticides and the diversity of microarthropods are both very high. Data showing field effects of pesticides on soil fauna are rather scanty (JoY \& Chakravorty 1991,Chakravorty et al. 1995, Vig et al. 2006, Perry et al. 1997) and we still do not know a lot about the effects exerted by these xenobiotics on ecosystems. Therefore, there is a need for further studies examining the effects of pesticides on various levels of organization of soil fauna. Even if the toxic effects are exerted over a single species, they can cause a "domino effect" within the higher levels of the trophic pyramid, disturb the balance in the soil food web, and in consequence, affect the whole forest ecosystems, including the resistant species. Additionally, persistence of pesticides and their metabolites may significantly influence their long-term toxicity. Therefore, we decided to carry out a field experiment to check the effects of two pesticides - mancozeb and diflubenzuron - on soil microarthropods. Since soil fauna is not a target for these 2 chemicals, we could observe unintentional effects, which could not be observed if the soil fauna were to be a target, as the applied doses would then kill the animals. In our experiment, we used the pesticide concentrations that did not cause lethal effects. Hence, we could observe long-term effects of mancozeb and diflubenzuron on the microarthropod soil fauna. The following research questions were addressed: (1) Do the used pesticides influence soil fauna, and if yes, to what extent and in what time-scale? (2) Does the harmfulness differ among various taxa? (3) What are the possible effects of pesticide toxicity to the food web?

\section{MATERIAL AND METHODS}

\section{Pesticides}

Diflubenzuron [1-(4-chlorophenyl)-3-(2,6-difluorobenzoyl)urea] is classified as a slightly toxic pesticide (toxicity class III, EXTOXNET 2006), used to control insects on forest trees or shrubs (gypsy moths, forest tent caterpillars, evergreen eating moths, boll weevils). Its major metabolites are 4-chloroaniline and 4-chlorophenylurea. Diflubenzuron inhibits the production of chitin. The rate of its degradation in soil (its half-life) varies from 3 to 102 days. Under field conditions, diflubenzuron has a very low mobility (Dost et al. 1985, WAUchope et al. 1992). 
Mancozeb [manganese ethylenebis(dithiocarbamate)(polymeric)complex with zinc salt] is an ethylene bisdithiocarbamate. In soil, mancozeb is metabolized to ethylene thiourea (ETU), ethylene urea (EU), and ethylene bisisothiocyanate sulfide (EBIS). The data concerning persistence of these substances in soil are not consistent and the reported values vary from one to 165 days (WAUCHOPE et al. 1992, HANUMANTHARAJU \& AwASTHI 2004). Mancozeb, but not ETU, is unlikely to infiltrate groundwater (MEISTER 1992).

\section{Experimental plots and methods}

The plots were located within a small planted pine stand in the vicinity of the Adam Mickiewicz University campus on Morasko (Pozna, Poland). We selected 30 experimental plots, $1 \mathrm{~m}^{2}$ each. They were spaced at least $2 \mathrm{~m}$ apart. The plots were divided into 3 groups - the first 10 plots were exposed to mancozeb, the next 10 were exposed to diflubenzuron, and the last 10 were the control, i.e. not exposed to either of the 2 chemicals. Next, the pesticides were sprayed over the plots. Commercial pesticides were used: Dithane (Dow AgroSciences, a wettable powder with $80 \%$ of mancozeb within the formula) and Dimilin $480 \mathrm{SC}$ (Crompton Manufacturing Company, a suspension concentrate with $480 \mathrm{~g}$ of diflubenzuron within $1 \mathrm{dm}^{3}$ of the formula). The applied concentrations were: $240 \mathrm{mg}$ of mancozeb and $7.2 \mathrm{mg}$ of diflubenzuron per $1 \mathrm{~m}^{2}$.

Random soil samples were collected from late June (hot, dry summer until a relatively warm January: i.e. just before spraying on 26 June 2006, and next 1, 4, 7, 14, 28, 60, and 196 days after spraying (i.e. the last samples were collected on 8 January 2007).

Each soil sample was about $300 \mathrm{~cm}^{3}$, i.e. about $9 \mathrm{~cm}$ deep, from an area of $33 \mathrm{~cm}^{2}$. (Thus to calculate the number of individuals per $1 \mathrm{~m}^{2}$, the mean value per sample must be multiplied by 303) One sample from a part of each plot was taken. Live animals were extracted from each sample for 3 days, using a Tullgren funnel. The animals were preserved in $75 \%$ ethanol, genera were determined, and the number of individuals representing each genus was noted and also expressed as percentage of the control number. Then, genera were grouped in higher taxa: Actinedida (prostigmatid mites), Gamasina (predatory mites), Uropodina (saprophagous mites), Oribatida, Collembola (springtails), Insecta (only Pterygota, mainly larvae of Diptera and Coleoptera), and Myriapoda. The significance of differences in their abundance between the control and pesticide-exposed plots was calculated using the Student $t$ test, and $P<0.05$ was regarded as significant.

\section{RESULTS}

The analysed taxa included mites (46 families), insects (12 orders and myriapods ( 3 classes), and were sorted into the abovementioned groups (Table 1). The total number of collected animals was the lowest for diflubenzuron-treated samples, and the highest for control samples. Abundance of the tested groups was the highest on control plots for gamasine mites, springtails and myriapods, on mancozeb-treated plots for oribatid mites, and on diflubenzuron-treated plots for actinedid mites and 
Table 1. Total number of individuals found in samples collected during the experiment from the control, mancozeb-treated and diflubenzuron-treated plots

\begin{tabular}{|l|c|c|c|}
\hline \multirow{2}{*}{ Taxonomic group } & \multicolumn{2}{|c|}{ Total number of individuals (and \% of control)* } \\
\cline { 2 - 4 } & Control & Mancozeb & Diflubenzuron \\
\hline Actinedida (=Prostigmata) & 301 & 321 & 339 \\
& & $(106.64)$ & $(112.62)$ \\
\hline Gamasina & 859 & 626 & 520 \\
& & $(72.88)$ & $(60.54)$ \\
\hline Uropodina & 79 & 45 & 34 \\
& & $(56.96)$ & $(43.04)$ \\
\hline Oribatida & 2620 & 2679 & 2461 \\
& & $(102.25)$ & $(93.93)$ \\
\hline Collembola & 715 & 667 & 581 \\
& & $(93.29)$ & $(81.26)$ \\
\hline Insecta (mainly larvae) & 640 & 570 & 692 \\
& & $(89.06)$ & $(108.12)$ \\
\hline Myriapoda & 30 & 17 & 8 \\
& & $(56.67)$ & $(26.67)$ \\
\hline Total & 5244 & 4925 & 4635 \\
& & $(93.92)$ & $(88.39)$ \\
\hline
\end{tabular}

*Numbers in brackets show percentage values, compared to the control regarded as $100 \%$

insects (Table 1). However, we did not observe any significant differences in their abundance between pesticide-exposed and control samples.

- Actinedid and oribatid mites, and springtails did not show any clear, statistically significant trends in response to pesticide application (Figs. 1, 4, 5). However, some fine alterations and trends could be noticed within the tested groups:

- Actinedida and Uropodina showed sinusoid fluctuations of the mean number of individuals within control groups (Figs. 1, 3).

- The abundance of Gamasina (Fig. 2) exposed to diflubenzuron was more stable than that of Actinedida, Uropodina and Oribatida (Figs. 1, 3, 4).

- Gamasina, Uropodina and Myriapoda showed more than 15\% decrease in the total number of individuals on pesticide-exposed plots, as compared to controls (Gamasina: ca. 27\% and 40\%; Uropodina: 43\% and 57\%, Myriapoda 43\% and $73 \%$ for mancozeb and diflubenzuron, respectively). Springtails showed a considerable decrease for diflubenzuron only (ca. 19\%).

- As the time passed, populations of insects exposed to pesticides did not show any clear decrease, when compared to the control groups (Fig. 6).

- Myriapods exposed to diflubenzuron were close to extinction. As time passed, their fluctuations were smaller, and finally we did not find any myriapods in many samples. 


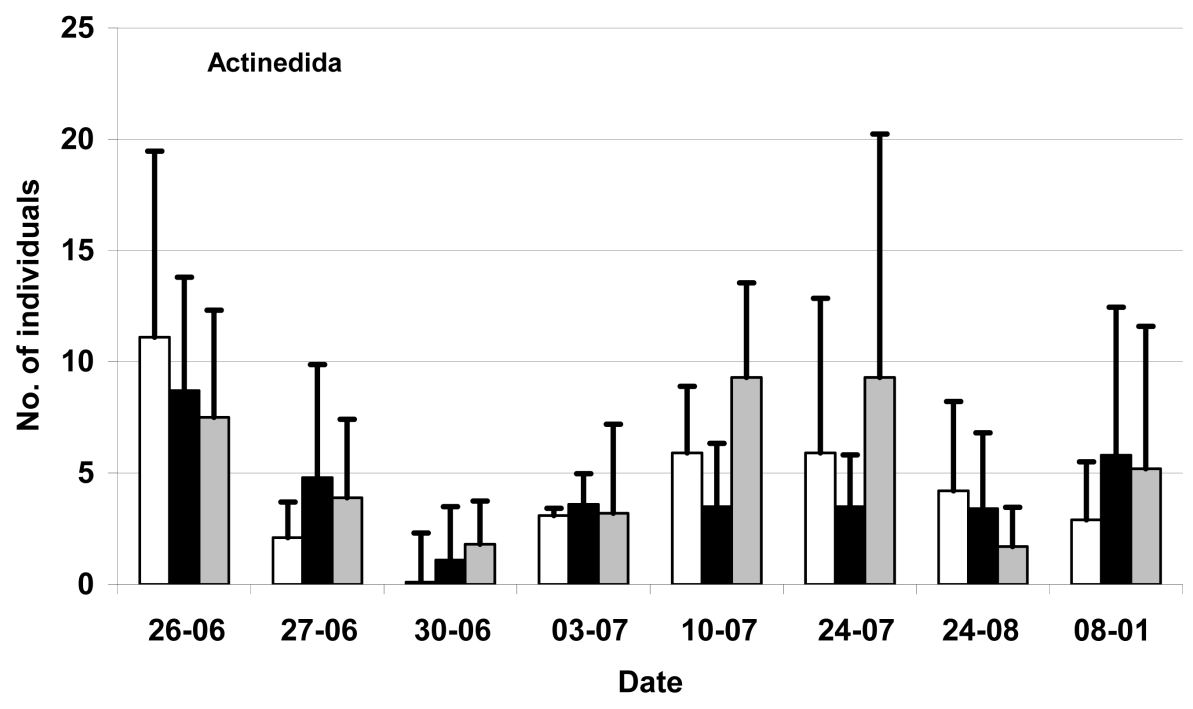

$\square$ Control $\square$ Mancozeb $\square$ Diflubenzuron

Fig. 1. Fluctuations of the number of actinedid mites per soil sample $\left(300 \mathrm{~cm}^{3}\right)$ on control and pesticide-exposed plots. Data are means $\pm \mathrm{SD}$

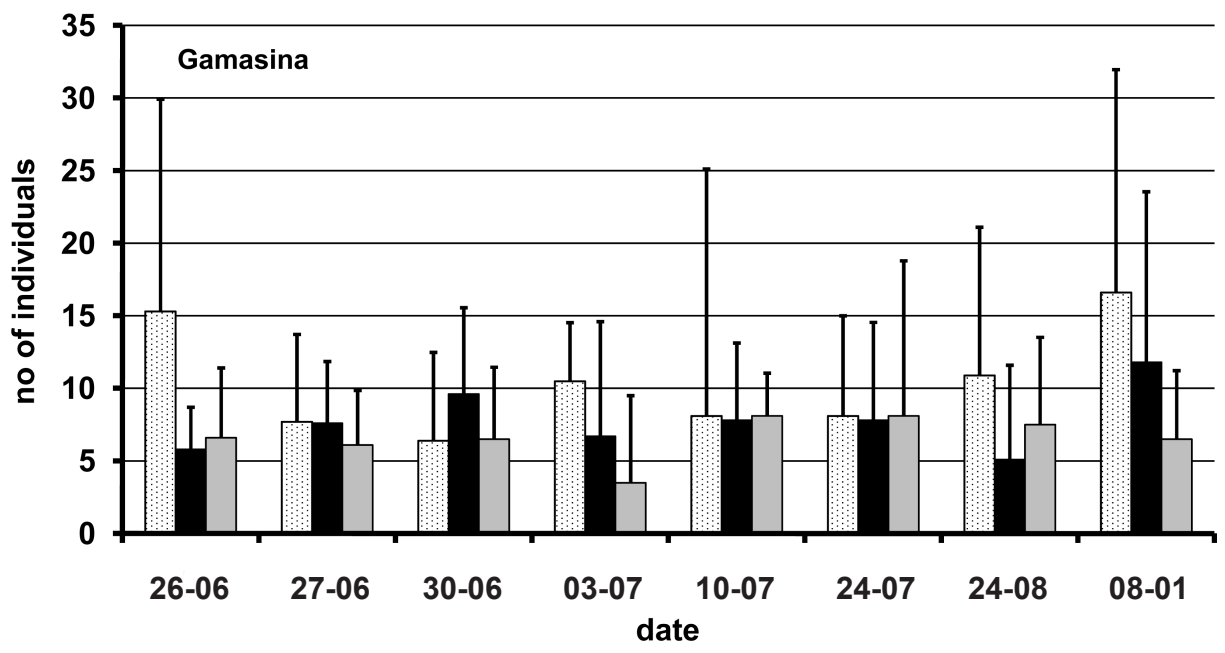

$\square$ Control Mancozeb $\square$ Diflubenzuron

Fig. 2. Fluctuations of the number of gamasine mites per soil sample $\left(300 \mathrm{~cm}^{3}\right)$ on control and pesticide-exposed plots. Data are means $\pm \mathrm{SD}$ 


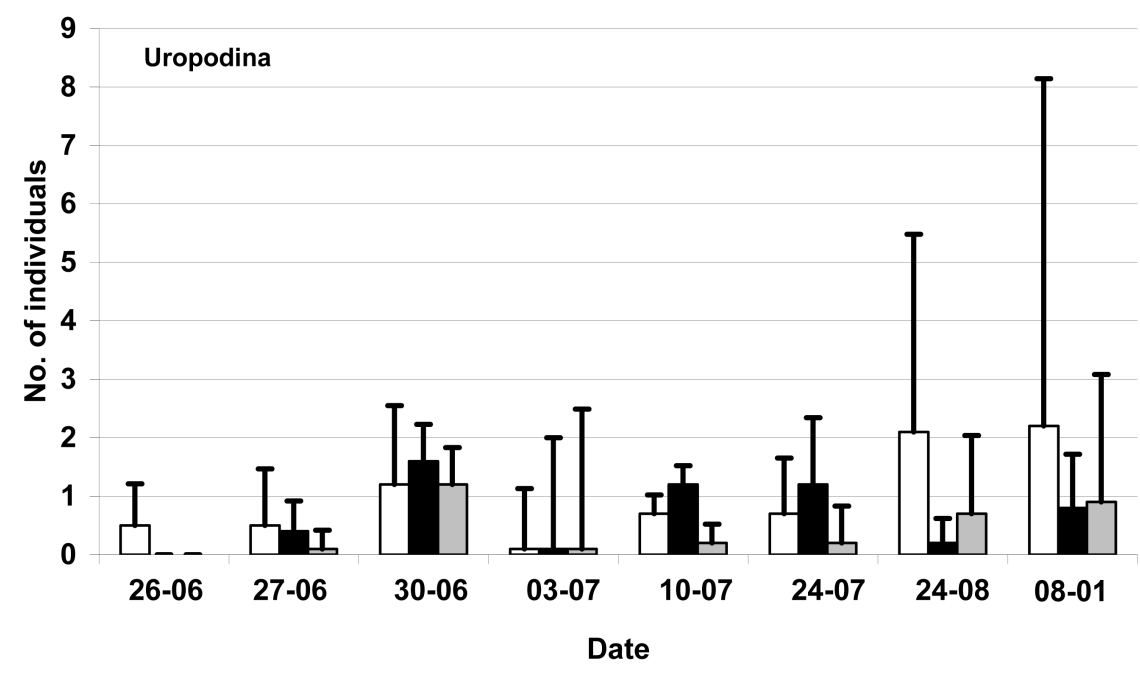

$\square$ Control $\square$ Mancozeb $\square$ Diflubenzuron

Fig. 3. Fluctuations of the number of uropodine mites per soil sample $\left(300 \mathrm{~cm}^{3}\right)$ on control and pesticide-exposed plots. Data are means $\pm \mathrm{SD}$

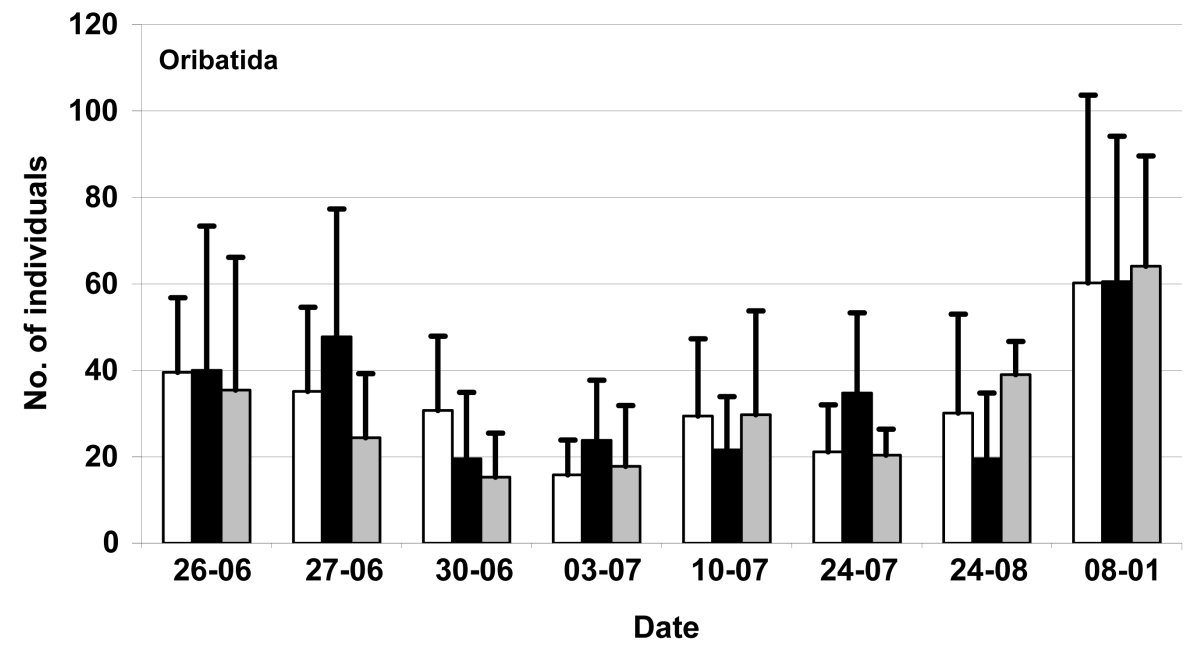

\section{$\square$ Control $\square$ Mancozeb $\square$ Diflubenzuron}

Fig. 4. Fluctuations of the number of oribatid mites per soil sample $\left(300 \mathrm{~cm}^{3}\right)$ on control and pesticide-exposed plots. Data are means \pm SD 


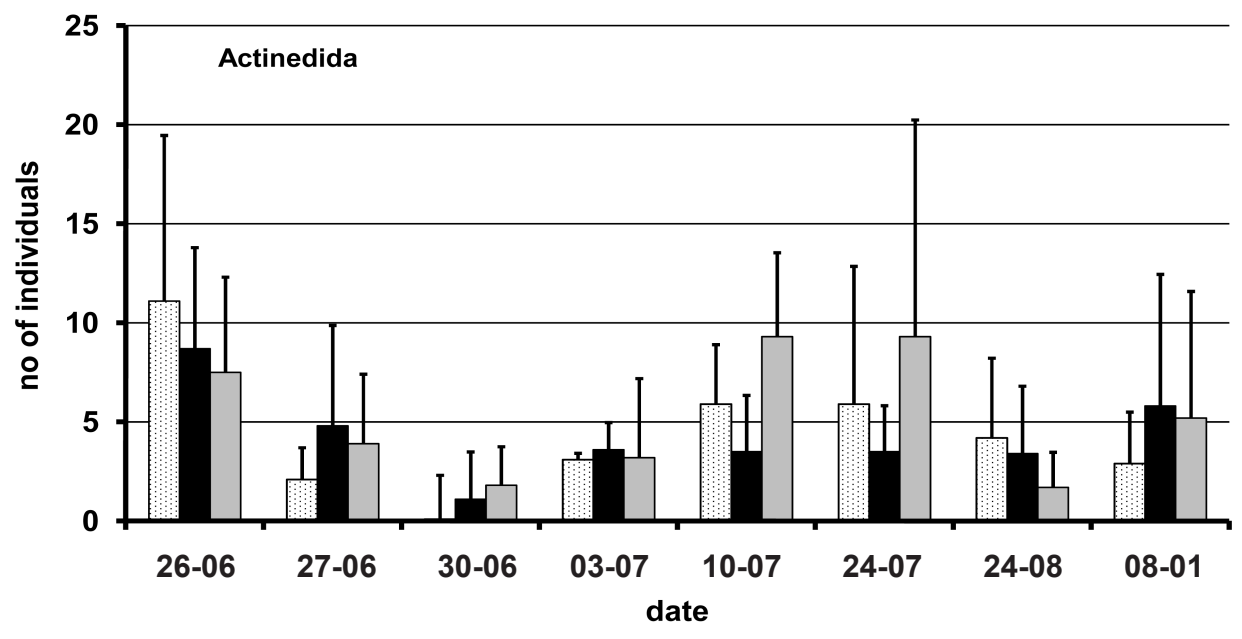

Gontrol a Mancozeb $\square$ Diflubenzuron

Fig. 5. Fluctuations of the number of springtails per soil sample $\left(300 \mathrm{~cm}^{3}\right)$ on control and pesticideexposed plots. Data are means $\pm \mathrm{SD}$

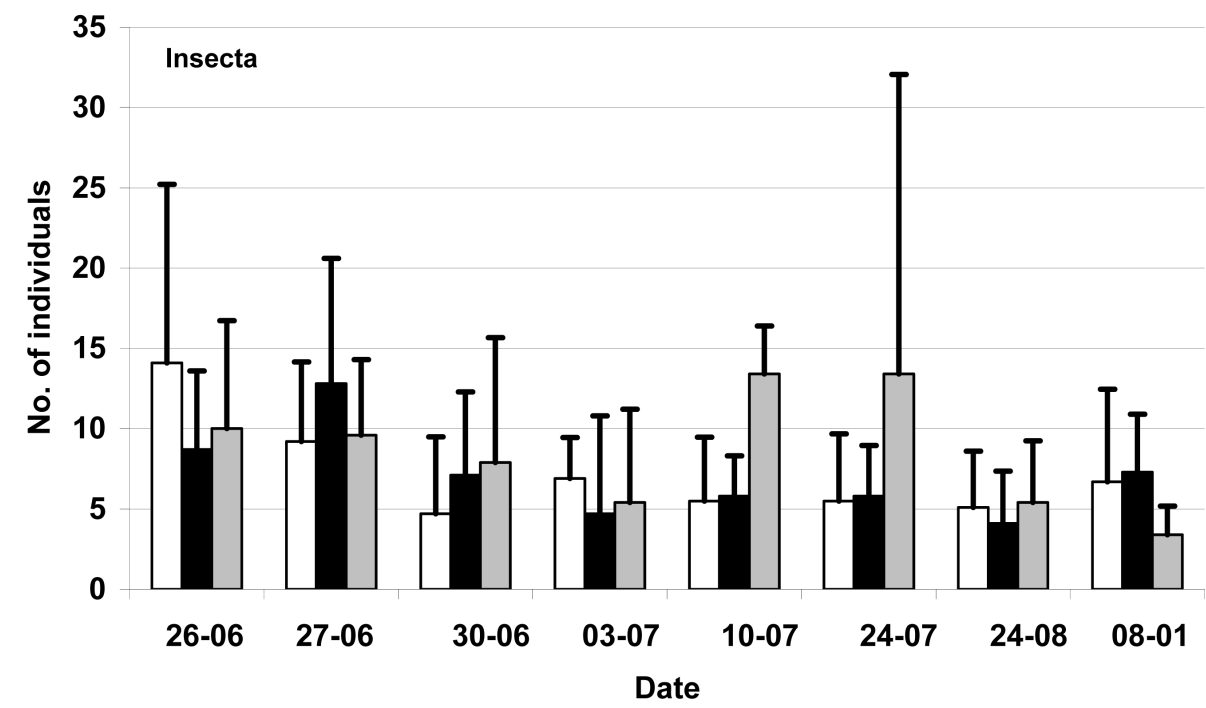

$\square$ Control $\square$ Mancozeb $\square$ Diflubenzuron

Fig. 6. Fluctuations of the number of insects per sample $\left(300 \mathrm{~cm}^{3}\right)$ on control and pesticide-exposed plots. Data are means $\pm \mathrm{SD}$ 


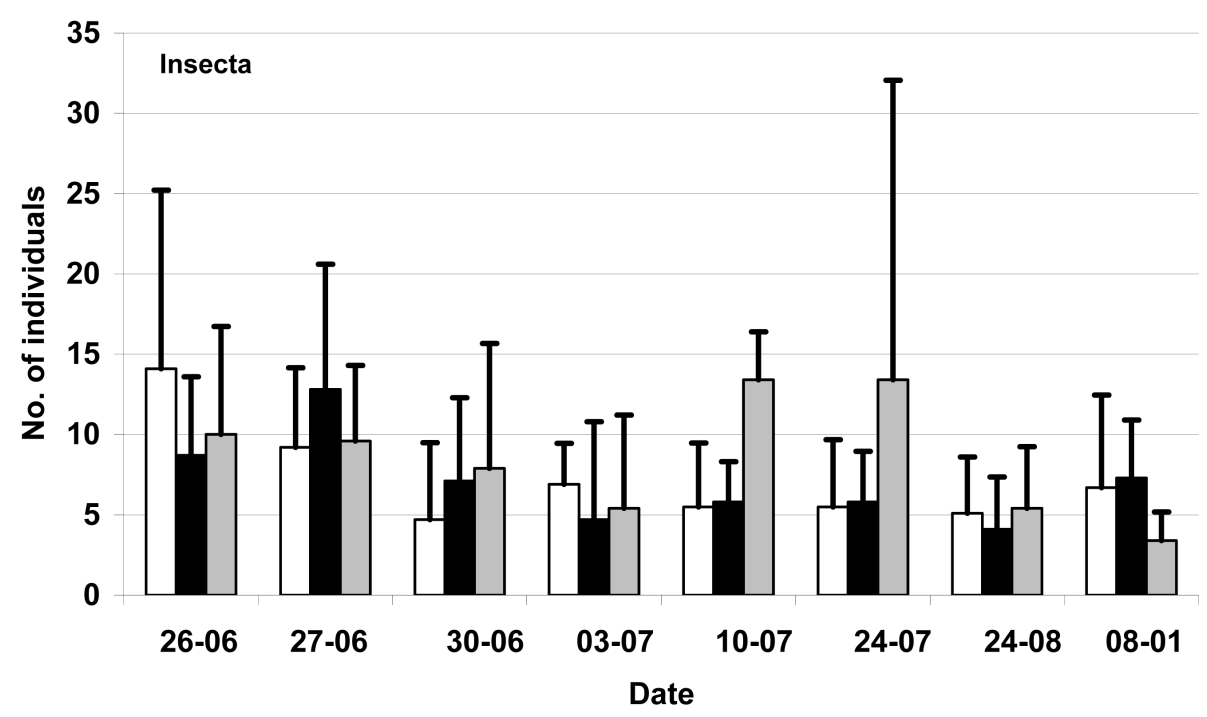

$\square$ Control $\square$ Mancozeb $\square$ Diflubenzuron

Fig. 7. Fluctuations of the number of myriapods per sample $\left(300 \mathrm{~cm}^{3}\right)$ on control and pesticideexposed plots. Data are means $\pm \mathrm{SD}$

\section{DISCUSSION}

Previously, we reported that the majority of taxa of microarthropods found in wood dust show some tolerance to short-term exposure to mancozeb (ADAMSKI et al. 2007). Data presented in the present paper can lead to the conclusion that a single pesticide spraying does not necessarily lead to massive mortality of invertebrates. The effects were even weaker than those observed in the abovementioned laboratory experiment. Perhaps, this can be explained by more intensive degradation of the active substance in soil than in the laboratory. Not only processes of biodegradation, but also weather conditions and soil persistence influence long-term toxicity of pesticides in the field, whereas laboratory conditions were stable. Since the summer of 2006 was very hot and dry in Pozna, the pesticides could not diffuse or migrate deeper when the experiment was carried out. Therefore, the soil habitat showed its buffering abilities. Similar results were obtained by PERRY et al. (1997) in their 36-month-long field experiment: the majority of the exposed taxonomic groups did not show lethal effects. One of the reported exceptions - Araneae - was not considered by us; we had not enough data to estimate the effect of mancozeb and diflubenzuron on these arthropods. PERRY et al. (1997) reported a lower density of observed Collembola (i.e. lower number of individuals). Similar results were also observed 
by other authors, who reported the susceptibility of springtails to several pesticides (Joy et al. 2005, VIG et al. 2006), and by our group, where more than $50 \%$ of these arthropods would theoretically die if the fungicide was sprayed over their habitats (ADAMSKI et al. 2007). In the present study we did not observe any significant decrease in the abundance of springtails during short-term and long-term exposure (Fig. 5). Therefore, risk assessment for this group must be strongly influenced by the type of soil and its characteristics.

Although not statistically significant, the decrease in the abundance of gamasine mites indicates the threat of pesticide spraying for soil fauna. The pattern of population development was similar to that observed on the control plots, but the total number of individuals decreased. As representatives of higher trophic levels, these predatory species can easily accumulate toxic chemicals, which is manifested in a decreased number of individuals.

Previously we reported that none of the tested wood-inhabiting actinedid families was fully susceptible to mancozeb, but that there was a high correlation between the concentration of the used pesticide and mortality (ADAMSKI et al. 2007). In the present work we did not observe any significant change in the abundance of these mites in soil. Perhaps the effect depends strongly on the represented species, their individual susceptibility, and then abundance, as well as on climatic conditions.

Observed differences in the effects of tested chemicals on various groups of soil fauna can be caused by numerous factors, e.g. animal size, metabolic processes, sclerotization of the cuticle, different niche, and localization within soil. The most endangered are the species that are found at the top of the humus. Therefore, relatively highly-sclerotized oribatid mites (as compared to other mites, e.g. Prostigmata), are relatively safe. Our results show that occasional spreading of pesticides does not affect significantly the soil fauna. However, frequent exposure can cause even a several-fold decrease in the abundance of oribatid mites (KRIVOLUCKIJ 1976). Therefore, repeated exposure may similarly affect springtails and weakly sclerotized actinedid mites, too. They are abundant within the top layer of soil and humus. Moreover, pesticides may lower animal fecundity (ADAMSKI \& ZiEMNICKi 2004, AdAMSKI et al. 2009), which was not checked in this work. Additionally, the natural controls (parasitoids, predators) may be weakened and so not affect harmful species with the intensity observed within control populations (Li et al. 2006, Babul Hossain \& Poehling 2006). All the abovementioned phenomena may influence populations after a longer time.

The presented data emphasize the protective role of soil as a dynamic environment, where the processes of degradation of xenobiotics are relatively fast (SUNDARAM 1991, HANUMANTHARAJU \& AWASTHI 2004), involving both physical degradation and biodegradation.

To sum up, we did not notice any short- or long-term significant decrease in abundance of soil microarthropod fauna, in response to exposure to the used pesticides. However, in some cases, the final decrease could be easily noticed (Gamasina, Uropodina Myriapoda, and to some extent Collembola). One must remember that ecotoxicologists often rely on values like no observable effect concentration (NOEC) and last observable effect concentrations (LOEC), which indicate very fine disturbances in trophic level, because even such insignificant changes may lead to serious 
perturbations within food webs. Therefore, side effects of xenobiotics on soil fauna should be carefully studied. The results encourage us to undertake further studies.

Acknowledgements: We would like to thank Prof. Helen Ghiradella, Department of Biological Sciences, State University of New York, Albany, for her valuable remarks, helpful suggestions, critical reading, and linguistic corrections of the manuscript.

\section{REFERENCES}

Adamski Z., BŁoszyk J., Bruin J., Ziemnicki K. 2007. Non omnia moriantur - toxicity of mancozeb on dead wood microarthropod fauna. Exp. Appl. Acarol. 42: 47-53.

Adamski Z., Machalska K., Chorostkowska K., Niewadzi M., Ziemnicki K., Hirsch H.V.B. 2009. Effects of sublethal concentrations of fenitrothion on beet armyworm (Lepidoptera: Noctuidae) development and reproduction. Pestic. Biochem. Phys. 94: 73-78.

Adamski Z., Ziemnicki K. 2004. Side effects of mancozeb on Spodoptera exigua (Hübn.) larvae. J Appl. Entomol. 128: 212-217.

Addison J.A., Trofymow J.A., Marshall V.G. 2003. Abundance, species diversity, and community structure in successional coastal temperate forest on Vancouver Island, Canada. Appl. Soil Ecol. 24: 233-246.

Babul Hossain M., Poehling H.M. 2006. Non-target effects of three biorationale insecticides on two endolarval parasitoids of Liriomyza sativae (Dipt., Agromyzidae). J. Appl. Entomol. 130: 360-367.

Chakravorty P.P., Bose S., Joy V.C., Bhattacharya S. 1995. Biomonitoring of anticholinesterase pesticides in the soil: usefulness of soil Collembola. Biomed. Environ. Sci. 8: 232-239.

Charmillot P.J., Gourmelon A., Fabre A.L., Pasquier D. 2001. Ovicidal and larvicidal effectiveness of several insect growth inhibitors and regulators on the codling moth Cydia pomonella L. (Lep., Tortricidae). J Appl. Entomol. 125: 147-153.

Dost F.N., Wagner S.L., Witt J.M., Heumann M. 1985. Toxicological Evaluation of Dimilin (Diflubenzuron). Oregon State University, Extension Service Toxicology Information Program, Department of Agricultural Chemistry, Corvallis, OR. 9-29.

Extoxnet (2006) Extension Toxicology Network Pesticide Information ProWles. URL http://extoxnet.orst.edu/pips/mancozeb.htm. Accessed 16 November 2006.

Hanumantharaju T.H., Awasthi M.D. 2004. Persistence and Degradation of Metalaxyl, Mancozeb fungicides and its Metabolite Ethylenethiourea in soils. Ind. J Environ. Health. 46: 312-231.

Joy V.C., ChaKravorty P.P. 1991. Impact of insecticides on nontarget microarthropod fauna in agricultural soil. Ecotoxicol. Environ. Saf. 22: 8-16.

Joy V.C., Pramanik R, Sakar K. 2005. Biomonitoring insecticide pollution using non-target soil microarthropods. J Environ Biol 26:571-577.

KRIVoluCKIJ D.A. 1976. Rol' pancirnych klescej v biogeocenozach. Zool. Ż., 55: 226-236.

Li D-X., Tian J, Shen Z-R. 2006. Effects of pesticides on the functional response of predatory thrips, Scolothrips takahashii to Tetranychus viennensis. J. Appl. Entomol. 130: 314-322.

Meister R.T. (ed.). 1992. Farm Chemicals Handbook '92. Meister Publishing Company, Willoughby, $\mathrm{OH}$.

Perry W.B., Christiansen T.A., Perry S.A. 1997. Response of soil and leaf litter microarthropods to forest application of diflubenzuron. Ecotoxicology. 6: 87-99.

Reuveny H., Cohen E. 2004. Resistance of the codling moth Cydia pomonella (L.) (Lep., Tortricidae) to pesticides in Israel. J. Appl. Entomol. 128: 645-651.

SUNDARAM K.M.S. 1991. Spray deposit patterns and persistence of diflubenzuron in some terrestrial components of a forest ecosystem after application at three volume rates under field and laboratory conditions. Pesticide Sci. 32: 275-293. 
VIg K., Shigh D.K., Sharma P.K. 2006. Endosulfan and quinalphos residues and toxicity t o s o i 1 microarthropods after repeated applications in a field investigation. J. Environ. Sci. Health B 41: 681-692.

Wauchope R.D., Buttler T.M., Hornsby A.G. Augustinn-Beckers P.W.M., Burt J. P. 1992. SCS/ ARS/CES Pesticide properties database for environmental decisionmaking. Rev. Environ. Contam. Toxicol. 123: 1-157. 